


\title{
Políticas públicas e outra perspectiva de avaliação: uma abordagem antropológica
}

\author{
Public policies and other evaluation \\ perspective: an anthropological approach
}

\author{
* Alcides Fernando Gussi \\ ** Breynner Ricardo de Oliveira
}

\section{Resumo}

Este artigo problematiza outros enfoques de avaliação para a compreensão das políticas públicas em diferentes contextos culturais, sociais e econômicos a partir da construção de parâmetros de avaliação distintos daqueles indicados pelo modelo técnico-formal de avaliação. Propõe-se uma ruptura com essa visão ortodoxa ao assumir que a avaliação de políticas públicas desconsidera os atores sociais envolvidos nas políticas, suas agendas e interesses, tornandoos invisíveis. Ao introduzir o conceito de trajetória, base para a construção de uma avaliação sob a abordagem antropológica, outro paradigma avaliativo emerge, configurando-se como um ethos epistemológico mais estruturado e crítico, alargando as bases conceituais e metodológicas.

Palvras-chave: avaliação, políticas públicas, metodologia em avaliação, epistemologia.

\begin{abstract}
This article discusses other evaluation approaches for the understanding of public policies in different cultural, social and economic contexts, based on the construction of evaluation parameters which are distinct from those indicated by the formal-technical evaluation models. It intends to oppose to this orthodox view by assuming that the evaluation of public policies disregards the social actors involved in policies, their agendas and interests, making them invisible. By introducing the concept of trajectory, the basis for an evaluation under the anthropological approach, another evaluative paradigm emerges, setting itself up as a more structured and critical epistemological ethos, and broadening the conceptual and objective framework.
\end{abstract}

Keywords: evaluation, public policies, evaluation methodology, epistemology

\footnotetext{
* Universidade Federal do Ceará

E-mail:agussi@uol.com.br 


\section{Introdução}

Neste artigo, analisamos outras perspectivas teóricas e metodológicas que se contrapõem a modelos de avaliação de políticas públicas regidas pelos marcos de regulatórios do Estado e do mercado. Ao incorporar paradigmas emergentes no campo da avaliação de políticas públicas, pretendemos apresentar e problematizar outro enfoque de avaliação para a compreensão da ação das políticas públicas - uma avaliação sob a abordagem antropológica - que incorpora, em seu escopo epistemológico, a diversidade de atores sociais e institucionais, e os contextos em que são implementadas as políticas.

Na última década do século passado, sobretudo no Brasil, nos rumos da Nova Gestão Pública, a agenda governamental impôs a avaliação como elemento constitutivo da gestão, nos contornos dos critérios de eficiência administrativa propostos por uma agenda liberal. Nesse período, a avaliação de políticas públicas tornou-se exigência de organismos internacionais, como o Banco Mundial, que passaram a condicionar empréstimos, notadamente na área social, a indicadores de resultados, a serem produzidos por avaliações sistemáticas de políticas e programas governamentais (BANCO MUNDIAL, 2004).

Contudo, há uma década, com o crescimento quantitativo e a importância das políticas sociais fomentadas pelo Estado brasileiro, a avaliação de políticas públicas começou a ser problematizada quanto à sua forma, usos e intencionalidades políticas. Em um cenário marcado pela emergência da sociedade civil e da necessidade de se criar mecanismos de controle social, impõem-se perguntas: para que avaliar? Como avaliar? Avaliar, para quem? Estas perguntas colocam em questão pressupostos da agenda neoliberal e seus modelos avaliativos e, remetendo a contradições do Estado e sua ação, encaminham outra pergunta: qual, enfim, o sentido de avaliar políticas públicas?

Essas perguntas remetem para a necessidade de construção de outros parâmetros de avaliação que vão além de definições operacionais conduzidas por modelos avaliativos preconcebidos e se distanciem da agenda política e do modelo técnico-formal de avaliação, ampliando o horizonte político, analítico e metodológico da avaliação de políticas públicas.

O artigo está estruturado em três seções: (i) A primeira apresenta as principais características da agenda de avaliação sob a perspectiva da Nova Gestão Pública, compreendida como um modelo de avaliação de cunho técnico-formal ancorado em uma proposição epistemológica funcional e positivista.

(ii) Na segunda, propõe-se uma ruptura com essa visão ortodoxa ao assumir que a avaliação de políticas públicas desconsidera os sujeitos sociais envolvidos nas políticas, suas agendas e interesses, tornando-os invisíveis. Ao dar visibilidade a essas questões, assume-se que a avaliação pode e deve ser compreendida a partir de condicionantes e constructos teóricos que extrapolam objetivos meramente regulatórios e administrativos. 
(iii) A terceira seção avança nas discussões introduzidas na seção dois ao incorporar os contextos sociopolíticos e culturais nacionais, regionais e locais, onde políticas se efetivam e as contradições nelas inerentes se evidenciam. Apresentam-se elementos para a construção de outro paradigma avaliativo que se configura como um ethos epistemológico mais estruturado e crítico, alargando as bases conceituais e metodológicas para o campo, ao delinar uma proposta que denominamos de avaliação sob a abordagem antropológica a partir da construção das trajetórias das políticas (GUSSI, 2008).

\section{Avaliação sob a perspectiva da Nova Gestão Pública}

Há, indiscutivelmente, um processo de reforma em curso nos diversos governos centrais. Esse cenário de reforma tem imposto ao Estado uma nova agenda, resultado da dinâmica sociopolítico-econômica que tem marcado os diversos governos nacionais. No que se refere à capacidade responsiva do Estado, ou, em outras palavras, a formulação e implementação de políticas públicas, identifica-se também alterações que são o reflexo desse contexto em constante transformação.

O Estado já não mais é o único articulador dos interesses e das demandas dos atores públicos. Em outras palavras, as políticas públicas, entendidas aqui como ações objetivas do Estado, deixam de ser exclusividade do setor público e incorporam duas outras esferas decisórias: o terceiro setor e o setor privado. Isso significa que os atores políticos ou os grupos de interesse constituídos têm outras esferas de interlocução para buscar que suas demandas recorrentes sejam contempladas por meio de diferentes políticas públicas.

Neste novo paradigma, da Nova Gestão Pública, o Estado assume um papel estratégico de articulador e direcionador, compartilhando a sua autoridade e delegando competências para um conjunto de instituições que, eventualmente, tornar-se-ão uma rede articulada de agentes promotores de uma sinergia entre as várias ações implementadas pelos governos e seus parceiros.

Essa articulação entre as diversas esferas de mediação de interesses promove um intercâmbio de atributos e competências para os agentes públicos e privados, o que contribui para a resignificação de conceitos que agora deixam de ser rígidos. Há, portanto, uma clara aproximação entre as várias culturas organizacionais envolvidas, o que certamente tem contribuído para a construção de um novo ethos público.

Delineia-se, portanto, um espectro de relações entre atores políticos que exige da administração pública a manutenção de um canal de prestação de contas e avaliação das ações implementadas, funcionando como um mecanismo de acesso multilateral entre o Estado e a sociedade organizada. Em outras palavras, governos devem ser accountables, isto é, capazes de responder aos diversos grupos de interesse sobre seus atos e decisões políticas. Nesse sentido, deve haver um conjunto de mecanismos de avaliação que empreguem ferramentas institucionais e não institucionais baseadas na 
ação de múltiplas associações de cidadãos, movimentos ou mídias, atores estes que são capazes de dinamizar o jogo político na medida em que trazem novas questões para a agenda pública, além de pressionar ou influenciar o processo decisório e, ainda, expor os erros e falhas do governo.

Assim, o desempenho e a eficácia dos governos dependem também desses mecanismos de controle, tarefa básica para que esse processo de reconfiguração do Estado aconteça. Nessa direção, os controles pela lógica dos resultados e pela competência administrada ganham novos contornos. $\mathrm{O}$ primeiro diz respeito à neces-sidade de os governos prestarem contas à sociedade acerca da efetividade de suas políticas e programas, além de assegurar que a estrutura administrativa funcione dentro de novos princípios de produtividade e desempenho. Essa perspectiva é fortemente vinculada à definição de metas e objetivos claros que permitam tanto à Administração mensurá-los quanto à sociedade fiscalizá-los. Dessa forma, o Estado estará rompendo com a lógica autorreferenciada da burocracia, trazendo a sociedade civil organizada para o interior do processo, inclusive em relação aos mecanismos de controle.

No que se refere à competência administrada, há uma tendência de que o Estado abandone o caráter monopolista que revestia a provisão de serviços e bens públicos. Nesse contexto, alarga-se a perspectiva de que a oferta de bens e serviços pode - e deve - ser equacionada através de uma rede articulada de agentes competitivos, gerenciados por provedores privados ou públicos, mas não exclusivamente estatais.

Tal pressuposto é indispensável para a Nova Gestão Pública. Muito mais do que um conceito abstrato, a condição de accountability para a administração pública nesse contexto pós-reforma é crucial para que a capacidade operacional e estratégica dos governos seja maximizada. Isso porque o componente político do processo decisório não pode ser ignorado ou relativizado. Pelo contrário, políticas públicas implementadas, avaliadas e monitoradas por governos nesse novo paradigma são, em maior ou menor grau, resultado de um complexo jogo de interesses em que a administração pública é apenas um dos múltiplos atores. É nesse sentido que uma rede de interesses e estratégias se configura, razão pela qual o setor público tem incorporado novas e distintas ferramentas de gestão, avaliação e monitoramento que melhor suportem esse novo modelo e contemplem os atores envolvidos.

Nesse contexto, as representações de eficácia e eficiência são distintas para burocratas, avaliadores e cidadãos. Os primeiros e os segundos têm a capacidade de analisar os processos internamente, corrigindo-os e/ou aperfeiçoando-os a fim de satisfazer suas agendas, que podem encerrar diversos interesses (corporativos, políticos, sociais, individuais, dentre outros). O desafio para os cidadãos reside na capacidade de serem - ou não - capazes de atribuir valor (ou significado) a essas questões porque tais ganhos podem - ou não - ser tangíveis. A tangibilidade do ganho é uma das condições para que o cidadão reconheça a modernização ou as respostas do Estado. Em suma: a avaliação - e o avaliador - entra no jogo e, portanto, configura-se como um elemento integrante da arena política e da agenda governamental. 
Este cenário nos leva à perspectiva avaliativa, fomentada pelos organismos internacionais, como o Banco Mundial e Banco Interamericano de Desenvolvimento e suas políticas de financiamento, que remetem a uma avaliação nos marcos políticos neoliberais. No Brasil, essa perspectiva tomou forma com a Reforma de Estado implementada nos anos 1990, quando se impôs um modelo de avaliação da gestão pública ajustado às demandas do Banco Mundial (BRESSER PEREIRA, 1998; BANCO MUNDIAL, 2004).

A essa agenda política circunscreve-se um modelo de avaliação de programas, projetos e políticas, sobretudo governamentais, baseados em critérios pré-definidos de eficiência, eficácia e efetividade dos mesmos. Quase sempre reduzidas à dimensão econômica, essas avaliações têm por intuito demonstrar o sucesso ou fracasso das políticas a partir da construção de indicadores, notadamente estatísticos, que revelam a otimização da relação custo-benefício, previamente calculada, em relação ao investimento realizado na execução de das políticas.

É preciso frisar que esse modelo não dá conta de tratar das contradições do Estado, considerando aqui, segundo Santos e Avritzer (2003), suas possibilidades de construir marcos emancipatórios, de cunho democrático, rumo à universalização de direitos, entre critérios de igualdade e equidade, que se impõem a partir dos movimentos da sociedade civil. Tal modelo circunscreve uma forma de avaliar associada a um campo político de afirmação de um Estado regulatório, regido dentro das regras de liberalização do mercado, em que as políticas devam estar circunscritas e, como decorrência disso, devam ser avaliadas.

Na próxima seção apresentamos uma ruptura com essa visão liberal ao assumir que a avaliação de políticas públicas deve incorporar os distintos atores sociais e institucionais, suas agendas e interesses, tornando-os invisíveis. Ao trazer à tona essas questões a partir das contribuições da Sociologia e da Teoria Econômica, entendemos que a avaliação pode ser compreendida a partir de condicionantes e constructos teóricos que extrapolam objetivos meramente regulatórios e prescritivos.

\section{Uma ruptura: a Economia Política da Avaliação}

Ao assumir que a avaliação encerra em si mesma um conjunto de elementos que fazem com que esse processo adquira contornos políticos relevantes, tornandose parte do próprio itinerário avaliativo -, pode-se perceber a relação com a teoria econômica na medida em que os agentes e os avaliadores podem ser considerados rentseekers ou, literalmente, caçadores de renda'. Assim, seus resultados, em termos de bem-estar social, ficam vinculados ao quadro institucional e organizacional, em que os agentes buscam maximizar seus interesses, que podem - ou não - estar alinhados com os objetivos institucionais e/ou organizacionais. Nessa perspectiva, as avaliações podem tornar-se meramente figurativas ou documentos padronizados com vistas a satisfazer requisitos legais, como a prestação de contas, por exemplo. 
Nesse sentido, a contribuição de Downs (1966;1999) é importante porque, a partir de sua análise sobre as organizações e o processo decisório no interior das instituições, pode-se recolher um conjunto de evidências que se aplicam ao campo da avaliação, aqui compreendida com um processo que está em curso no interior das organizações, mas que não está voltado única e exclusivamente para as mesmas.

Downs (1999) afirma que o objetivo de seu estudo é apresentar uma teoria que explique o processo de tomada de decisão no interior das organizações e permita ao analista fazer previsões sobre aspectos do comportamento de uma organização e incorporá-los em uma teoria mais generalizada da tomada de decisão social. Para isso, o autor parte de duas premissas. A primeira postula que os agentes que integram esse universo (bem como os demais agentes sociais e os avaliadores) agem racionalmente, isto é, buscam atingir seus objetivos de forma racional. Em outras palavras, são maximizadores de utilidade. A segunda pressupõe que os agentes (pode-se incluir os avaliadores neste modelo), de modo geral, possuem um conjunto complexo de objetivos a serem atingidos, inclusive poder, renda, prestígio, segurança, conveniência, lealdade (a uma ideia, instituição ou nação), orgulho do trabalho excelente e desejo de servir ao interesse público.

A partir das formulações de Downs, podem-se extrair algumas conclusões que se aplicam ao campo da avaliação: (1) os custos de transação ${ }^{2}$ no processo avaliativo de obtenção da informação são elevados porque requerem tempo, esforço e recursos financeiros para obter dados e decodificar significados, traduzindo-os de forma inteligível e aplicada; (2) os tomadores de decisão envolvidos na avaliação são indivíduos que têm racionalidades limitadas e, por isso, não conseguem tomar decisões pareto-eficientes ${ }^{3}$; (3) os agentes e avaliadores operam sob condições de incerteza e, ainda que a obtenção de informação possa reduzir essa assimetria, resta considerável quantidade de incerteza na tomada de decisões. Assim, tendo em vista o tempo que gastam tomando decisões, o número de questões que podem considerar simultaneamente e a quantidade de dados referentes a qualquer problema que podem absorver, os atores estão longe de maximizar a utilidade, comprometendo o processo decisório.

Conforme foi destacado, as organizações existem para garantir que os interesses definidos sejam ordenados e convergentes e, portanto, alcançados. Isso implica coordenar os esforços e os interesses de um conjunto de pessoas que fazem parte da estrutura e exercem suas funções em diferentes níveis hierárquicos. Como a articulação não acontece espontaneamente e os interesses dos agentes não são necessariamente convergentes com os da organização, os custos de transação tendem a ser elevados, o que justifica a existência da autoridade hierárquica, da racionalização dos processos e do ordenamento burocrático. A avaliação está, portanto, contingenciada por esse grupo de fatores e seu resultado dependerá de como esses elementos combinam-se internamente. 
Em outras palavras, as organizações públicas e privadas são estruturas marcadas pelo conflito, externalizado pela divergência de interesses entre os indivíduos e elas, configurando-as como arenas políticas que podem influenciar os rumos dos processos avaliativos. Ao contrário da teoria weberiana, Downs (1966) afirma que burocracias públicas e privadas não operam todo o tempo alinhadas, que seus integrantes não são neutros e imparciais e tampouco estão comprometidos única e exclusivamente com os objetivos das instituições nas quais estão inseridos.

Segundo o autor, conflitos de interesse emergem sempre que os agentes tiverem percepções distintas sobre os objetivos organizacionais, sobre o contexto e sobre a conjuntura à qual estão submetidos. Assumindo que essas variáveis são dinâmicas e que mudam o tempo todo, presume-se facilmente que vão existir conflitos sempre, afetando potencialmente o itinerário da avaliação. Diferenças de percepção podem ser explicadas tanto do ponto de vista organizacional quanto do valorativo. Dependendo da função exercida na organização, da formação e do nível hierárquico ocupado, pode haver interpretações distintas acerca de um objeto. O mesmo se aplica a crenças, valores e ideologias, que também podem influenciar na percepção e no comportamento dos indivíduos.

O problema do agente-principal também pode ser uma variável importante quando somada às questões levantadas por Downs. Segundo Varian (1994), referese às dificuldades que podem surgir entre os agentes econômicos por causa da informação assimétrica e incompleta. Assim, quando um principal (que, em tese, está em posição superior) contrata um agente (que, em tese, está em posição de dependência ou subordinação), se a quantidade de informação acumulada por este for superior ao estoque do primeiro, pode-se dizer que o principal corre o risco de ser "capturado", invertendo-se a relação.

A economia e a ciência política observaram os problemas inerentes à delegação de autoridade legislativa para agências burocráticas. A aplicação da legislação está aberta à interpretação burocrática, que cria oportunidades e incentivos para o burocrata desviar-se das intenções ou preferências dos legisladores, capturando-os. A mesma situação pode acontecer entre as agências reguladoras e as organizações reguladas, quando as últimas acabam manipulando as primeiras.

No caso da avaliação e do avaliador, a captura pode acontecer, por exemplo, na relação contratado versus contratante, quando as avaliações sofrem distorções impostas ao avaliador pelo órgão contratante. Da mesma forma, o órgão ou setor pode ser capturado pelo avaliador quando este modifica os objetivos e o escopo da avaliação, absorvendo evidências do campo que não faziam parte das premissas inicialmente acordada ou "impondo" uma agenda que está alinhada com os interesses da instituição que o mesmo representa.

Limitações técnicas e especificidades de formação ou especialização na função cotidiana contribuem para que cada indivíduo possua um quantum de informação, diferente em relação ao dos outros. Assim, ainda que esses atores tenham os mesmos 
objetivos, interesses e percepções, suas atitudes e comportamentos são diferentes porque a quantidade de informação e expertise acumulada é diferente para cada um deles. Novamente, as implicações para a avaliação são claras, afastando-a da ideia de neutralidade/horizontalidade que o paradigma instrumental equivocadamente sugere.

Tomando-se como referência uma organização pública qualquer, independente da esfera e do setor em que esteja situada, pode-se afirmar que, de acordo com Downs (1966;1999), os diversos integrantes da estrutura setorial desse órgão não estão necessariamente alinhados e comprometidos com os mesmos princípios e objetivos. Isso não significa que esses profissionais estejam descomprometidos com os objetivos finalísticos da instituição, mas que podem divergir sobre como alcançá-los. Agentes de um setor, por exemplo, podem ter interesses e percepções diferentes em relação a sujeitos de outros departamentos; coordenadores não devem estar, necessariamente, alinhados com os subordinados, com sua chefia imediata ou com a liderança máxima, entre inúmeras combinações possíveis, que também podem ser aplicadas às demais unidades de gestão que atuam no mesmo local e/ou no mesmo território.

É por isso que, invariavelmente, as organizações contam com estruturas de autoridade hierárquicas: alguém (ou um grupo) deve decidir e, decidindo, deve conduzir a organização rumo ao atingimento de objetivos. O mesmo raciocínio se aplica a avaliação: qual órgão a contratou? Qual setor? Sob qual conjuntura política? Quais as finalidades oficiais e reais? Qual o orçamento disponível? Qual a importância do órgão/setor na hierarquia? Há alguma agenda "oculta" por parte da instituição que fará a avaliação, a ponto de configurar uma relação de captura? Há chances de o órgão capturar o avaliador?

Em relação aos conflitos, afloram os provocados pela interdependência de comportamento entre indivíduos em diferentes setores/áreas de uma organização. Essa interdependência pode ser, segundo Downs, de quatro tipos: (1) puramente funcional, quando as funções exercidas por um indivíduo repercutem nas de outro, interconectadamente; (2) alocacional, quando dois ou mais padrões de comportamento são completamente desvinculados funcionalmente, mas podem se articular quando a distribuição de recursos orçamentários é levada em consideração; (3) informacional, quando os estoques de informação não são simetricamente diluídos entre os agentes envolvidos, desequilibrando a relação entre as partes e potencializando o risco da captura; e (4) funcional-alocacional, quando (1) e (2) acontecem ao mesmo tempo.

Os tipos (2) e (4) indicam que o orçamento é uma arena de conflitos por definição. Como o orçamento das organizações públicas é, de modo geral, separado na execução do gasto e integrado na arrecadação dos recursos, o uso do "caixa único" cria graus diferentes de interdependência alocativa entre as que integram a Administração Pública. Sendo, pois, o "cobertor sempre mais curto", disputas por orçamento entre secretarias, ministérios, autarquias, fundações, etc. (além das disputas internas em cada um dos órgãos) têm de acontecer. Em última instância, o processo de avaliação 
de políticas públicas e programas é contigenciado por esses conflitos, não sendo, necessariamente, fruto da pressão realizada pelos diversos grupos de interesse que representam as demandas da sociedade. A avaliação de políticas públicas pode ser, portanto, decidida e hierarquizada em função da quantidade de dinheiro e de informação disponíveis para sua execução, independentemente da importância estratégica.

Na arena política da avaliação, os processos burocráticos inerentes ao processo avaliativo também são interdependentes da alocação de recursos uma vez que são financiados pelo mesmo orçamento. Isso significa que, para um órgão da Administração Pública, projetos, programas e ações concorrem entre si, para "abocanhar" fatias maiores dos recursos orçamentários disponíveis, o que dá visibilidade aos conflitos. Mais uma vez, a existência de uma estrutura hierárquica é crucial para assegurar que a alocação de recursos priorize critérios políticos e/ou técnicos, ainda que nem sempre contemplem etapas avaliativas. Em outras palavras, tais disputas nessa arena não significam que a avaliação está assegurada como uma dimensão ou etapa da política ou programa. Pelo contrário, ainda é frequente não fazerem parte do processo de formulação e implementação.

Especificamente em relação ao tipo (3), além de coordenar os processos e os indivíduos para que os interesses sejam convergentes e os objetivos alcançados, a burocracia deve viabilizar o controle do fluxo de informação entre seus membros e o avaliador, tanto no nível horizontal quanto no vertical, criando uma rede de comunicação a fim de assegurar que não se desperdicem recursos com excesso nem se comprometam processos por falta de informação ou porque a mesma está assimetricamente alocada entre as diversas partes interessadas. De todo modo, os custos de transação podem ser elevados em função do problema dos filtros informacionais e/ou dos desequilíbrios oriundos da falta de simetria em cada nível hierárquico, repercutindo, novamente, no processo avaliativo.

Como há um fluxo de informação de cima para baixo, de baixo para cima e no mesmo nível, sempre há um individuo (ou mais de um), em dado nível hierárquico, que é responsável por filtrar, resumir, explicar, interpretar e repassar. Dependendo de como acontece, a forma de processar a informação é mudada completamente, alterando/enviesando a decisão do indivíduo ou grupo do próximo nível, razão pela qual os custos informacionais são sempre elevados e, para o caso das avaliações, a assimetria entre os envolvidos e os resultados obtidos não necessariamente atenderão os objetivos inicialmente definidos.

Mesmo com a existência de procedimentos formais que conformam as avaliações e com uma série de regras a serem observadas, há espaço para o surgimento de espaços porosos, líquidos e ocultos que também modificarão o curso das avaliações. Segundo Crozier (1981) e Selznick (1966), estes elementos formam o aspecto oculto das instituições e, no caso em questão, das avaliações. Eles pactuam regras de comportamento, recompensas, sanções, crenças e expectativas. Esses elementos, 
coletivamente agrupados, definem sua composição em termos de afinidade, objetivos e interesses. É por isso que se diz que as organizações - e, por extensão, as avaliações são resultado de interações construídas e que as relações estabelecidas são decisivas para compreender como se estruturam.

Em relação aos indivíduos (burocratas e avaliadores), sabe-se que a interação, no interior das organizações e fora delas, requer altos níveis de representação e capacidade adaptativa, uma vez que, dependendo do grupo de que participam, os sujeitos ocupam posições diferenciadas, quer no nível dos deveres, quer na esfera dos direitos. Dessa forma, segundo Downs (1966), cada pessoa avalia sua posição em função dos grupos que ocupa dinamicamente e calcula sua conduta de modo a satisfazer as próprias expectativas e as do grupo em questão, garantindo tanto a convergência de interesses quanto a identidade com os membros envolvidos.

O papel dos grupos sociais emerge, portanto, como um dos fatores que permitem compreender a dinâmica organizacional para além da perspectiva institucional. De modo geral, pode-se dizer que um grupo social é um conjunto de indivíduos vinculados uns aos outros por valores, expectativas, afinidades e interesses, com o intuito de satisfazer as necessidades pessoais. É possível afirmar, portanto, que a participação do indivíduo (e do avaliador) no grupo ocorre de forma mais ou menos homogênea. Dependendo da intensidade, da importância e do papel dinâmicotemporal que exerce, o vínculo estabelecido tende a ser diferente.

Esse raciocínio pode ser feito ao contrário, especialmente quando se considera o ambiente organizacional. Sabe-se que o indivíduo (e o avaliador) se vincula a um grupo em função de valores que, nesse momento, são relevantes para ele. Entretanto é possível ser aplicado ao indivíduo algum tipo de enquadramento ou ordenamento a fim de garantir que os objetivos do grupo ou da organização sejam alcançados e/ou preservados. Especificamente no lado institucional, as funções de liderança cumprem exatamente esse papel, lançando mão de vários mecanismos de controle e motivação.

Para Downs, os indivíduos (aí incluídos os avaliadores) tendem a considerar todo o conjunto de seus interesses e não apenas os relacionados ao desempenho de um papel. Ao fazer isso, esses agentes abrem espaço para que os poderes constituídos sejam usados para alcançar outros objetivos, como status e poder próprio. Segundo Oliveira (2007), "essas estruturas informais acabam por modificar o modelo de comportamento da organização como um todo, redirecionando grande parte das atividades dos membros para manipulação de poder, renda e prestígio, em vez de atingir as propostas formais da organização" (p. 278). Nesse contexto, cada indivíduo possui uma função social e motivos privados para desempenhá-la. Diz a autora: "a função social é o pacote de objetivos sociais aos quais suas ações servem, é a atividade que se desenvolve, que é valorizada pelos outros e que forma contribuição para a divisão do trabalho" (p. 279). Embora a função social e os motivos privados possam ter objetivos em comum, nunca são totalmente idênticos. 
Segundo Oliveira, essa diferença ocorre por duas razões. A primeira reside no fato de que cada pessoa desempenha uma função formal na divisão do trabalho, durante parte da vida, mas também desempenha outros papéis, em outras dimensões sociais, que consomem tempo e energia. Segundo Downs, esses papéis geram desejos, atitudes e comportamentos que, inevitavelmente, influenciam ações. A segunda razão está associada ao autointeresse.

De acordo com Oliveira (2007), "os agentes também valorizam os próprios atos em termos da congruência com seus interesses pessoais" (p. 280). Dessa forma, cada agente burocrático, burocrata e/ou avaliador possui objetivos variados por diversos motivos: buscar poder dentro da organização/departamento ou fora, mover-se por acréscimos na renda ou por dinheiro, querer prestígio, buscar conveniência, expressa pela resistência a mudanças no comportamento que aumentem o esforço pessoal e mudanças que reduzem o esforço, maximizar a segurança, definida como baixa probabilidade de futuras perdas de poder, prestígio, renda ou conveniência, orientarse por lealdade pessoal, lealdade ao grupo de trabalho, à organização, a um governo ou a uma nação, sentir orgulho por desempenho proficiente no trabalho e desejo de servir ao interesse público, definido como o que cada agente crê que a organização deve fazer para melhor desempenhar sua função social.

Entendemos que, nos contornos dessa análise, que entende a incorporação de atores e contextos sociopolíticos e culturais nacionais, regionais e locais onde políticas se efetivam e as contradições neles inerentes, apresentam-se elementos para a construção de outro paradigma avaliativo que se configura como um ethos epistemológico mais estruturado e crítico, alargando as bases conceituais e metodológicas para o campo da avaliação, proposto a seguir.

\section{Uma avaliação sob uma abordagem antropológica}

Como é possível construir outra forma de avaliação de políticas públicas que contemple as contradições do Estado e se afaste de modelos operacionais, e que seja assentada em uma perspectiva epistemológica e metodológica mais ampla? Enfim, como buscar um (outro) sentido para avaliar políticas públicas?

Inicialmente, é preciso considerar que avaliar políticas públicas trata-se de um processo de natureza sociopolítico e cultural. Como ponto de partida, compreendemos, nos termos de "uma avaliação em profundidade" (RODRIGUES, 2008; 2011), que a avaliação constitui um processo multidimensional e interdisciplinar na medida em que se pretende contemplar várias dimensões (sociais, culturais, políticas, econômicas, territoriais) envolvidas nas políticas públicas e realizar interfaces analíticas e metodológicas advindas de distintos campos disciplinares, sobretudo o das ciências sociais aplicadas.

Nessa avaliação, Rodrigues (2008) privilegia a abordagem interpretativa, em especial pelo esforço de tratar dados de diferentes tipos levantados no contexto do 
campo da política em avaliação, como, por exemplo: entrevistas em profundidade, aliadas à observação, análise de conteúdo de material institucional e apreensão e compreensão dos sentidos e significados atribuídos no decorrer do processo descrito pela política ou programa. Portanto, alia-se a uma perspectiva teóricometodológica que considera tanto a avaliação quanto a política ou programa de forma multidimensional em uma leitura extensiva, detalhada e densa.

Na busca por construir os marcos para uma compreensão de políticas, programas e projetos, a avaliação em profundidade de Rodrigues (2008) aponta para quatro dimensões consideradas essenciais para uma avaliação, a saber: (i) a análise de conteúdo, (ii) o contexto da formulação, (iii) a extensão temporal e territorial e (iv) a construção de trajetórias das políticas, sobre as quais denvolveremos adiante. Com esse propósito metodológico, os desenvolvimentos e usos de cada uma das quatro dimensões são primordiais para os encaminhamentos do campo compreensivo em avaliação de políticas públicas.

Essa perspectiva de avaliação em profundidade das políticas públicas implica em uma dupla dimensão: a primeira, analítica, refere-se à compreensão das políticas públicas, no esteio das configurações contemporâneas do Estado; a segunda dimensão, metodológica, implica na construção de metodologias que se filiem à perspectiva processual, multidimensional de avaliação ${ }^{4}$.

Primeiramente, a dimensão analítica da avaliação de políticas públicas deve considerar os seguintes aspectos, propostos por Carvalho e Gussi (2011): (1) as novas configurações dos padrões contemporâneos de intervenção do Estado; (2) o jogo de interesses sociais, no âmbito das relações de poder; (3) o universo cultural, onde os diferentes sujeitos envolvidos nesta política se movimentam e se constituem e (4) as agendas públicas e ações políticas dos distintos sujeitos.

Trata-se, pois, da compreensão epistemológica de uma avaliação, ampla e abrangente, que visa analisar políticas públicas dentro do padrão de intervenção do Estado e suas contradições, considerando suas relações com distintos sujeitos sociais, envolvidos nas políticas, imersos em universos de sentidos e significados, nos contextos de suas culturas.

Coadunada a esta dimensão analítica, associa-se a construção de desenhos metodológicos que permitam efetivar este processo avaliativo em profundidade, com aportes operativos que deem conta das exigências analíticas ao tratar a complexidade do objeto avaliativo.

A metodologia de avaliação em profundidade de políticas públicas não obedece a modelos a priori, mas sim constitui uma construção processual do avaliadorpesquisador, que faz suas escolhas metodológicas ao longo do processo avaliativo. Isso implica um exercício de reflexão constante do avaliador quanto ao lugar sociopolítico, exigindo uma vigilância permanente para não cair nas armadilhas da subjetividade, dos seus próprios interesses e da sua vinculação institucional com a política pública, o que pode implicar em vieses avaliativos (CARVALHO E GUSSI, 2011). 
Considerando que as premissas da "avaliação em profundidade" (Rodrigues, 2008, 2011) circunscrevem a metodologia de avaliação de políticas públicas, nossa proposta metodológica para a avaliação de políticas públicas remete a um diálogo com o campo disciplinar da antropologia, sobretudo com o que Cardoso de Oliveira (1996) denomina de "o horizonte antropológico". Duas perspectivas orientam esse campo: a postura relativista e a observação participante.

No que tange à postura relativista, o avaliador deve tentar compreender como os diferentes atores envolvidos concebem as políticas e entendem os seus resultados e impactos a partir de referenciais próprios de sua cultura. Nessa postura, a avaliação tende a ser multirreferenciada, pois contempla os vários destinatários das políticas e os significados que dão a elas, sem que se atribua a esses significados uma hierarquia de valores que tende a julgar sob o prisma de um único agente envolvido na política.

Contudo, essa postura não se constitui a priori: ela é uma construção do avaliador que deve fazer sua imersão no cotidiano da política, onde ela se implementa. Tratase de ir a campo e construir, por meio da observação participante e das técnicas de pesquisa a ela concernentes, a experiência in loco das políticas públicas, que constituirá a base empírica de dados para a sua avaliação (Lejano, 2011).

Posto o horizonte antropológico que orienta a nossa perspectiva metodológica, entendemos que, para avaliar, é necessário construir, nos dizeres de Geertz (1989), uma "descrição densa", na qual se busca interpretar os diferentes significados acionados publicamente pelos atores no contexto das ações que envolvem as políticas. A partir desse ponto de vista antropológico, propomos que o avaliador deve percorrer as trajetórias da política, compreendendo-a como um devir submetido a incessantes transformações, na medida em que essas trajetórias têm como base as dimensões culturais das instituições e dos grupos sociais envolvidos com as políticas, que circunscrevem os seus resultados (GUSSI, 2008).

A noção de trajetória constitui um aporte fundamental para a ampliação da nossa perspectiva avaliativa (GUSSI, 2008). Para tanto, entende-se essa noção a partir de Bourdieu em seu ensaio "A ilusão biográfica" (1996). O autor compreende como trajetória "uma série de posições sucessivamente ocupadas por um mesmo agente (ou um mesmo grupo), em um espaço ele próprio em devir e submetido a transformações incessantes" (BOURDIEU, 1996, p. 81). Dessa maneira, Bourdieu não busca interpretar a vida como um conjunto coerente e orientado, que se desenrola seguindo uma ordem lógica, mas sim como algo que se desloca no espaço social e não está vinculada apenas a um agente, mas sim a distintos agentes sociais.

A partir dessa compreensão, a noção de trajetória emerge como referencial metodológico estratégico para a compreensão dos processos sociais, construindo um diálogo entre temporalidades e territorialidades, revelando uma dimensão histórica, coletiva e social. Nesse sentido, por exemplo, por meio das narrativas e relatos de vida construídas a partir de entrevistas em profundidade, é possível formular a compreensão do contexto social em que estão inseridos os atores (GUSSI, 2005). 
Similarmente ao que propõe Bourdieu (1996) e à sua noção de trajetória biográfica, sustentamos a ideia que uma política pública não tem um sentido único e, portanto, está circunscrita a ressignificações de acordo com os fluxos organizacionais, processos burocráticos e modificações interpretativas que vão se desdobrando dentro e fora dos vários espaços institucionais a qual a política está vinculada. Em outras palavras, há que se levar em conta os deslocamentos da política nesse itinerário institucional e entre os distintos grupos sociais aos quais a mesma se destina. (GUSSI, 2008).

Partindo dessa ideia, a avaliação de uma política pública deve acompanhar as suas trajetórias, os seus distintos deslocamentos entre os diferentes atores institucionais e destinatários dessa política, em um processo de imersão no campo, onde as políticas são implementadas. Para tanto, deve-se definir estratégicas metodológicas participativas, buscando os vários entendimentos acerca da política, ou seja, seus objetivos, ações e resultados, compreendidos por diferentes atores (agentes institucionais, público destinatário e partes interessadas), associando aspectos verificados in loco aos distintos contextos socioeconômicos, políticos e culturais. A proposição é construir metodologicamente, no campo, a experiência da política pública nesses contextos, como representado no Diagrama $1^{5}$.

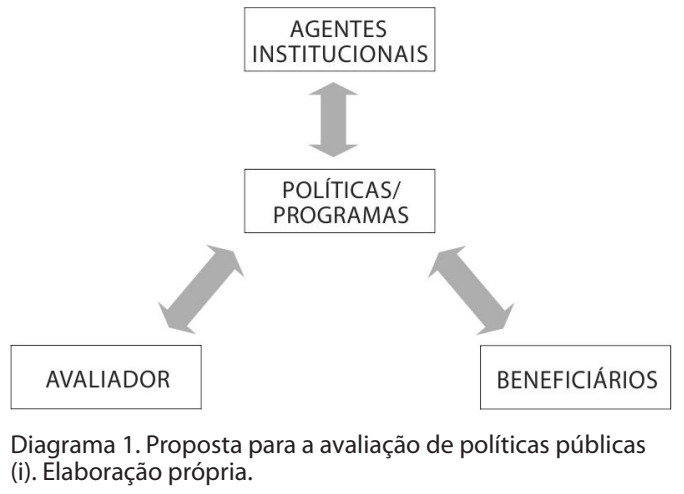

Há que se atentar, no Diagrama 1, para o lugar do avaliador nesta proposta. Sua concepção sobre a política deve ser reconstruída a partir de sua imersão no campo. Isso significa que, assumindo uma postura relativista, deve contrapor as suas próprias concepções sobre a política com as de outros atores. Assim, na medida em que compreende o que os outros atores dizem, é possível avaliar essa política de forma a não estabelecer, de uma vez por todas, uma verdade sobre ela, mas sim uma compreensão eticamente ponderada acerca da política avaliada.

Mas um esforço analítico adicional deve ser empreendido a partir da construção densa das trajetórias da política. É fundamental que os resultados de uma pesquisa avaliativa sejam interpretados em relação às configurações do Estado e suas contradições, conforme apresentado no Diagrama 2. 


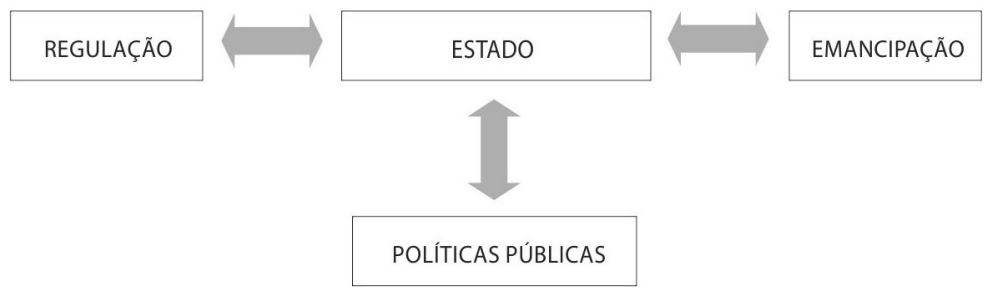

Diagrama 2. Proposta para a avaliação de políticas públicas (ii). Elaboração própria.

Em outras palavras, avaliar sob uma perspectiva antropológica, ao mesmo tempo em que implica, metodologicamente, um esforço orientado para a compreensão e construção das trajetórias das políticas, impõe que se leve em conta a compreensão da ação do Estado e a busca do entendimento das mudanças advindas das políticas a partir de diferentes agendas, interesses e pontos de vista. Sua descrição deverá enfrentar a compreensão das dinâmicas da política, relacionando-as à agenda do Estado e circunscrevendo relações de poder consubstanciadas, dialeticamente, nas disputas políticas dos diferentes atores, entre perspectivas políticas regulatórias e/ou emancipatórias (SANTOS E AVRITZER, 2003).

\section{Considerações finais}

Em Sobre o Estado, Bourdieu (2014) discorre longamente acerca de diversas dimensões sociológicas que conformam e constrangem o Estado. Ao tomar emprestado do autor uma análise teleológica sobre o Estado, percebe-se que a mesma se aplica ao campo da avaliação sob o ponto de vista administrativo, regulatório e gerencial, quando o paradigma da Nova Gestão Pública parece ser a única alternativa possível: a avaliação é um consentimento, é a aceitação de uma "ideia".

Ainda que pareça que o campo da avaliação tenha caminhado na direção da "canonização" de um padrão (BOURDIEU, 2012) - o padrão-ouro das avaliações -, sacramentando a importância das estatísticas, dos standards e de certos enfoques metodológicos alinhados com o mainstream internacional (o "mercado" da avaliação), buscou-se, neste artigo, apresentar uma abordagem antropológica que considera a avaliação como um itinerário por meio da noção de trajetória. Ao fazer isso, defendeuse o entendimento de que esse padrão não é monolítico e homogêneo.

As formulações apresentadas oferecem uma contribuição ao campo da avaliação porque revelam outras dimensões que dão materialidade a esta temática, conferindo à mesma maior densidade teórico-metodológica, além de reconhecer as múltiplas concepções que fundamentam o campo, para além das visões mais normativas e com forte caráter instrumental. Assim, pode-se considerar que há nesta discussão o interesse de propor uma leitura alternativa sobre a avaliação, no sentido de contrapor o paradigma vigente, partindo-se da premissa de que aspectos aparentemente 
ocultos, ou ocultados pelas avaliações instrumentais, são determinantes para uma melhor compreensão das dinâmicas de uma avaliação, tanto do ponto de vista dos agentes quanto das arenas políticas envolvidas.

Contudo, entendemos que essa leitura analítica e metodológica da avaliação implica pensar outras premissas epistemológicas sobre ação política. Por exemplo, ao trazer a questão simbólica para a discussão sobre o Estado, Bourdieu (2014), em sua análise, confere centralidade aos códigos, ritos e símbolos, elementos que também são integrantes da dinâmica estatal. Isso nos permite assumir que há um jogo de cena que é fundamental considerar no percurso avaliativo, que inclui os burocratas, os avaliadores, as agências de avaliação e instituições públicas nacionais e internacionais, dentre outros atores que integram essas arenas decisórias. Esse mise en scene cotidiano (GOFFMAN, 2002) é também elemento decisivo do contexto e da conjuntura, indispensável nos relatórios produzidos pelos avaliadores.

O que podemos afirmar, por ora, é que a proposta de avaliação sob a perspectiva antropológica, aqui apresentada, implica no afastamento dos modelos formais universais de avaliação ao defender que aspectos invisíveis sobre atores, seus contextos e as políticas, advindos do trabalho de campo, sejam trazidos à tona durante o processo avaliativo e, no momento da apresentação dos resultados, sejam a eles incorporados.

Ao propormos tal abordagem, defendemos uma avaliação: (1) baseada na experiência empírica das políticas, atentando para como são executados no seu cotidiano institucional e fora dele; (2) assentada na construção das trajetórias das políticas em foco, associadas, metodologicamente, com histórias de vida (GUSSI, 2005); (3) participativa, com foco no ponto de vista de distintos sujeitos institucionais e beneficiários, que resulta numa compreensão hermenêutica da política e não no seu julgamento final; (4) que articule o texto do programa (marcos legais, conceitos, objetivos e ações) e os seus distintos contextos: econômico, político, social e cultural (LEJANO, 2011); (5) e que permita a formulação de novos indicadores socioculturais, construídos durante o trabalho de campo, chamando a atenção para outras dimensões quanto aos resultados das políticas, tais como, sociais, culturais, políticas e ambientais (GONÇALVES, 2008).

Finalmente, consideramos que a avaliação de políticas públicas sob a abordagem antropológica, como horizonte político e epistemológico a ser perseguido, permite revelar o potencial democrático de uma avaliação, de modo que essa se constitua em uma forma efetiva de controle social e de afirmação da cidadania e equidade. Mais do que isso, significa negar os modelos ortodoxos quase sempre afinados à perspectiva regulatória do Estado e às dinâmicas do mercado, apresentando-se como um referencial capaz de revelar, incorporar e analisar os embates, conflitos e dissensos resultantes das políticas públicas implementadas. 


\begin{abstract}
Notas
1 Definição de rentseeking é oferecida por Tollison \& Congleton (1988): é o gasto de recursos que visa a enriquecer a pessoa, aumentando a participação em quantidade fixa de riqueza. Em vez de criar riqueza, esse agente prefere tirar proveito de um processo de geração que já está em curso.

2 Os custos podem ser definidos como custos de negociar, redigir e garantir o cumprimento de um contrato ou das regras do jogo. A teoria econômica postula que os custos de transação se alteram de acordo com as características da transação e do ambiente competitivo. Segundo Varian (1994), a teoria tem como pressuposto o fato de os agentes possuírem racionalidade limitada, por estarem sempre propensos ao oportunismo. Como não têm conhecimento integral sobre o ambiente, não conseguem obter uma solução que maximize a eficiência.

3 Vilfredo Pareto desenvolveu a teoria da otimização e da eficiência econômica, segundo a qual uma situação em que nenhuma reorganização ou transação pode elevar a utilidade ou satisfação de um indivíduo, sem reduzir a utilidade ou satisfação de outro indivíduo, assegura uma condição de eficiência.

${ }^{4}$ Essas duas dimensões articulam-se na construção da perspectiva aqui apontada. Nesse sentido, Silva e Silva (2008), em suas elaborações sobre avaliação de políticas e programas sociais, aponta para esta articulação ao enfatizar a relação dialética entre as dimensões técnicas e políticas dos processos avaliativos.

5 Trata-se de uma proposição alinhada à perspectiva de Lejano (2011) para a análise de políticas, baseada na problematização da noção de experiência da política. Para este autor, a política deve ser compreendida em seu cotidiano, na prática dos atores sociais envolvidos com ela, em seus contextos específicos.
\end{abstract}

\title{
Referências
}

BANCO MUNDIAL. Monitorização \& Avaliação. Algumas ferramentas, métodos e abordagens. Washington, D.C., 2004.

BAUMAN, ZIGMUND. Modernidade líquida. Rio de Janeiro: Zahar, 2001.

BOURDIEU, P. Sobre o Estado. São Paulo: Companhia das Letras, 2014.

BOURDIEU, PIERRA. A ilusão biográfica. In: AMADO, Janaína; FERREIRA, Marieta de Moares (org.). Usos e abusos da história oral. Rio de Janeiro: Fundação Getúlio Vargas, 1996, p. 183-191.

BRESSER-PEREIRA, LUÍS CARLOS. Da administração pública burocrática à gerencial. In: BRESSER-PEREIRA, Luís Carlos; SPINK, Peter. (Org) Reforma do Estado e administração pública gerencial. Rio de Janeiro: Fundação Getulio Vargas, 1998, p. 141-172.

CARDOSO DE OLIVEIRA, ROBERTO. O trabalho do antropólogo: olhar, ouvir, escrever. Revista de Antropologia. São Paulo: USP, v. 39, n. 1, 1996.

CARVALHO, ALBA MARIA PINHO; GUSSI, ALCIDES FERNANDO. In: Perspectivas contemporâneas em Avaliação de Políticas Públicas. Seminário "Avaliação de Políticas Públicas em Tempos Contemporâneos". Mestrado em Avaliação de Políticas Públicas. Fortaleza: UFC, 2011 (inédito).

CROZIER, MICHEL. O fenômeno burocrático: ensaio sobre as tendências burocráticas dos sistemas de organização modernos e suas relações na França, com o sistema social e cultural. Brasília, DF: Universidade de Brasília, 1981.

DIMAGGIO, P.; POWELL, W. The Iron Cage Revisited: Institutional Isomorphism and Collective Rationality in Organizational Fields. American Sociological Review, v. 48, n. 2, apr., 1983.

DOWNS, ANTHONY. Inside bureaucracy. Boston: Little, Brown, 1966.

DOWNS, ANTHONY. Uma teoria econômica da democracia. São Paulo: EDUSP, 1999.

GEERTZ, CLIFORD. A interpretação das culturas. Rio de Janeiro: Guanabara, 1989. 
GOFFMAN, E. A representação do eu na vida cotidiana. São Paulo: Vozes, 2002.

GONÇALVES, ALÍCIA FERREIRA. Políticas Públicas, etnografia e a construção dos indicadores socioculturais. Aval - Revista de Avaliação de Políticas Públicas. UFC, número 1, p. 17-28, 2008.

GUSSI, ALCIDES FERNANDO. Apontamentos teórico-metodológicos para avaliação de programas de microcrédito. Aval - Revista de Avaliação de Políticas Públicas. UFC, número 1, p. 29-37, 2008.

. Pedagogias da experiência no mundo do trabalho: narrativas biográficas no contexto de mudanças de um banco público estadual. 2005. 356 f. Tese (Doutorado), Faculdade de Educação, Universidade Estadual de Campinas, Campinas, 2005.

HARRIS, J.; EVANS, T. Street-Level Bureaucracy, Social Work and the (Exaggerated) Death of Discretion. British Journal of Social Work. n. 34, p. 871-895, 2004.

HILL, MICHAEL. The Policy process in the Modern State. Third Edition.Prentice Hall, 1997.

LASWELL, H. D. Politics: Who Gets What, When, How. Cleveland, MeridianBooks.1936/1958.

LEJANO, RAUL P. Parâmetros para análise de políticas públicas: a fusão de texto e contexto. Campinas: Editora Arte Escrita, 2011.

LIPSKY, M. Street-level bureaucracy: dilemmas of the individual in public services. Nova York: Russell Sage Foundation, 1980.

MERTON, R. K. Estrutura burocrática e personalidade.In: CAMPOS, E. org. e trad. A Sociologia da Burocracia. 4. ed. Rio de Janeiro: Zahar. 1978, p.78-102.

MUSGRAVE, RICHARD ABEL; MUSGRAVE, PEGGY B. Finanças públicas: teoria e pratica. Rio de Janeiro: São Paulo: 1980.

MUSHENO, M.; MOODY, M. S. Cops, Teachers, Counselors-Stories from the front Lines of Public Service. Michigan: The Universityof Michigan Press, 2003.

OLIVEIRA, B. Gestão de políticas públicas regionais e locais. Ouro Preto: Universidade Federal de Ouro Preto, 2010.

OLIVEIRA, C. O Servidor público brasileiro: uma tipologia da burocracia. Revista do Serviço Público: vol. 58, n. 3, jul/set 2007.

PERROW, C. Análise Organizacional- Um Enfoque Sociológico. São Paulo: Atlas, 1981.

PERROW, C. Complex organizations: a critical essay. 3 ed. New York: Randomouse, 1986.

RODRIGUES, LEA CARVALHO. Propostas para uma avaliação em profundidade de políticas públicas sociais. Aval - Revista de Avaliação de Políticas Públicas. UFC, número 1, p. 7-15, 2008.

Avaliação de Políticas Públicas no Brasil: antecedentes, cenário atual e

perspectivas. In: PRADO, Edna Cristina; DIÓGENES, Elione Maria Nogueira (org.) Avaliação de Políticas Públicas: entre Educação \& Gestão Escolar. Maceió/AL, EDFAL, p. 37-55, 2011.

SANTOS, BOAVENTURA DE SOUSA e AVRITZER, LEONARDO. Introdução: para ampliar o cânone democrático. BOAVENTURA de Sousa Santos (Org). Democratizar a Democracia: os caminhos da democracia participativa. Porto: EdiçõesAfrontamento, 2003, p.39 a 69.

SELZNICK, PHILIP. TVA and the grass roots: a study in the sociology of formal organization. New York: Harper \&Row, 1966.

SILVA E SILVA, MARIA OZANIRA DA. Avaliação de políticas e programas sociais: uma reflexão sobre o conteúdo teórico e metodológico da pesquisa avaliativa. SILVA, Maria Ozanira (Org). Pesquisa avaliativa: aspectos teórico-metodológicos. São Paulo: Veras Editora: São Luis: GAEPP, 2008, p. 89-177. 
TOLLISON, ROBERT D.; CONGLETON, ROGER D. (Ed.). The economic analysis of rent seeking. Aldershoot: Edward Elgar Publishing Ltd, 1988.

TULLOCK, GORDON. Toward a mathematics of politics. Ann Arbor: University of Michigan, 1967. VARIAN, HAL R. Microeconomia: princípios básicos. Rio de Janeiro: Campus, 1994.

WEBER, M. Burocracia. In: GERTH, H. H. \& WRIGHT MILLS, C. (orgs.). Ensaios de Sociologia. 5 ed. Rio de Janeiro: Guanabara, 1982, p.212-265.

WILSON, JAMES Q. Bureaucracy: what government agencies do and why they do it. United States: Basic Books,1989. 